\section{UJMM

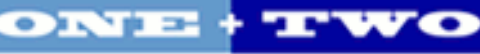

Volume 3 | 2011 Spring

\section{Undergraduate Journal of Mathematical}

Modeling: One + Two

2011

\title{
Roller Coasters Need Calculus Too!
}

Christina Marshall

University of South Florida

\author{
Advisors: \\ Masahiko Saito, Mathematics and Statistics \\ Jeff Hornick, Director of Design and Engineering, Busch Gardens \\ Problem Suggested By: Jeff Hornick
}

Follow this and additional works at: https://digitalcommons.usf.edu/ujmm

Part of the Mathematics Commons

UJMM is an open access journal, free to authors and readers, and relies on your support:

Donate Now

\section{Recommended Citation}

Marshall, Christina (2011) "Roller Coasters Need Calculus Too!," Undergraduate Journal of Mathematical Modeling: One + Two: Vol. 3: Iss. 2, Article 5.

DOI: http://dx.doi.org/10.5038/2326-3652.3.2.5

Available at: https://digitalcommons.usf.edu/ujmm/vol3/iss2/5 


\title{
Roller Coasters Need Calculus Too!
}

\begin{abstract}
Using the specifications of the given launch roller coaster, we were able to determine the position vector of the roller coaster as a function of time. After determining the position function, we took the derivative of this function to calculate the velocity of the coaster as a function of time. From this calculated velocity vector, we were able to determine the time required for the coaster to reach its maximum height. We substitute this time value back into the position function to determine the maximum height the launch roller coaster can obtain.
\end{abstract}

\section{Keywords}

Projectile Motion, Roller Coasters, Valley Out

\section{Creative Commons License}

\section{(c) (i) () $\Theta$}

This work is licensed under a Creative Commons Attribution-Noncommercial-Share Alike 4.0 License. 


\section{TABLE OF CONTENTS}

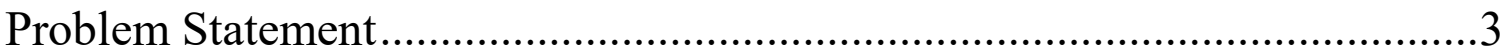

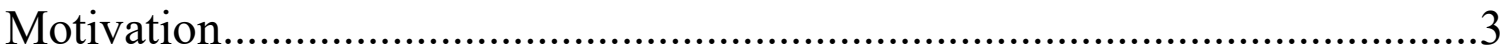

Mathematical Description and Solution Approach ......................................4

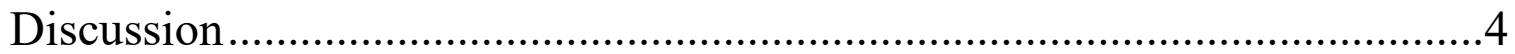

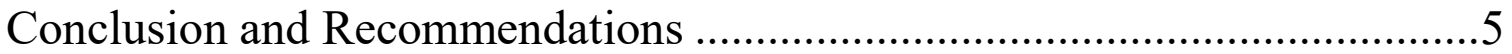

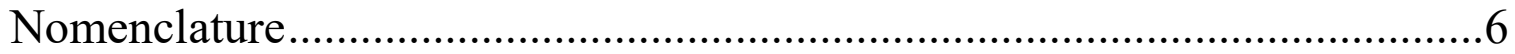

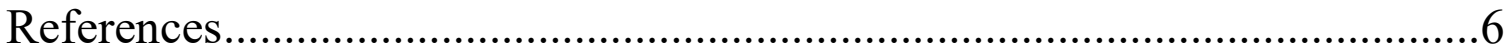

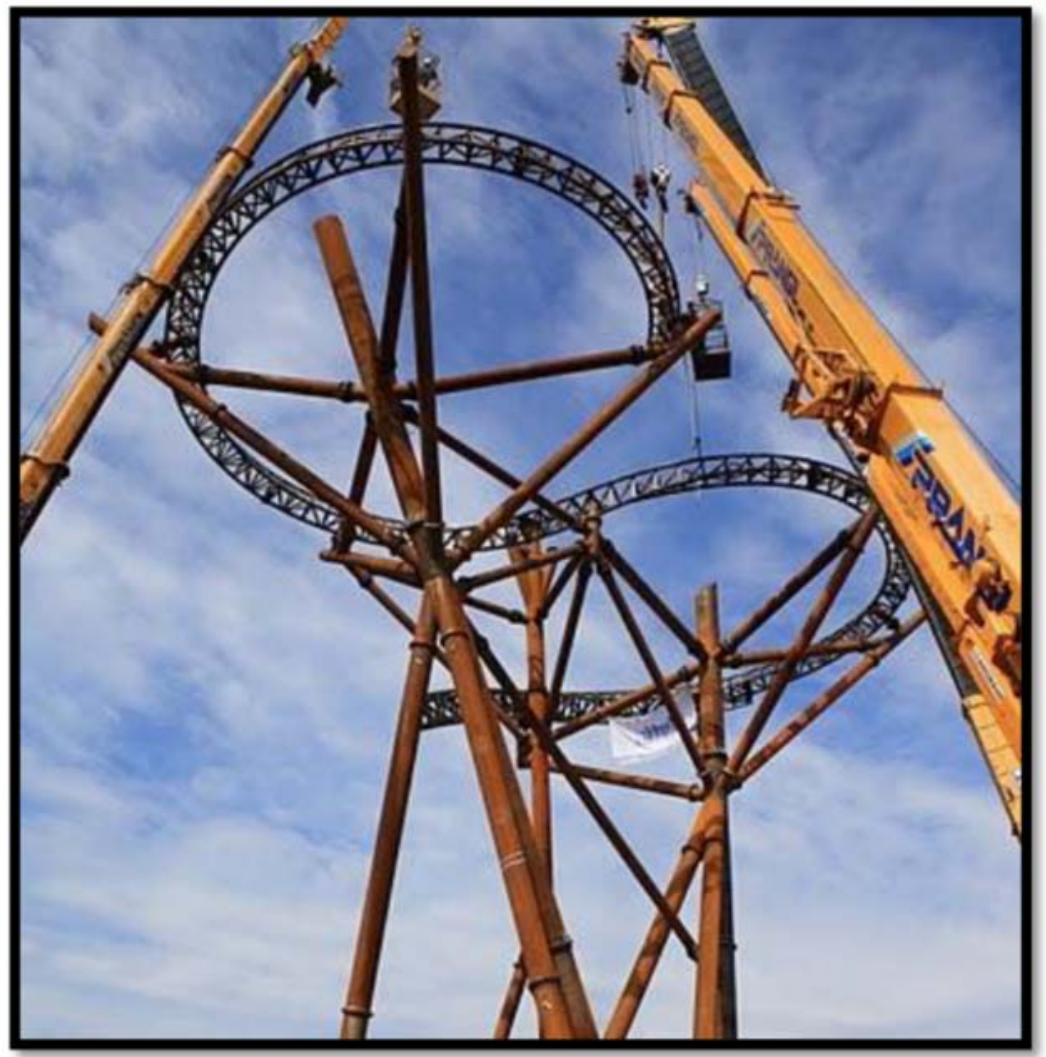




\section{PROBLEM STATEMENT}

Determine the position vector and find the maximum height of a launch roller coaster traveling with an initial velocity of $60 \mathrm{mph}$ with a height of $15 \mathrm{ft}$ from the ground. The roller coaster is launched from an angle of $30^{\circ}$.

\section{Motivation}

The launch roller coaster is a modern form of the classic amusement park ride. Unlike its predecessors who rely on a chain lift, the launch coaster initiates the ride by launching the coaster at high speed directly out of the gate. Vector calculus is a powerful tool for those in the business of ride design and creation. Calculus methods allow us to determine the maximum height attainable by a roller coaster before the track is even built. Without this knowledge a hill could be constructed too high and the roller coaster would "valley out." This term is used to describe what happens when the roller coaster is unable to continue of its path, ultimately leaving the coaster stuck on the lowest portion of the track. Amusement parks lose time and money from malfunctions such as "valleying out" since the coaster has to be towed back to the starting position. Doing all the appropriate calculations prior to the construction of the ride enables the roller coaster to run as efficiently as possible. 


\section{MATHEMATICAL DESCRIPTION AND SOLUTION APPROACH}

To determine the position vector of the roller coaster as a function of time we use a wellknown formula for projectile motion. Let $\boldsymbol{i}$ represent the unit vector in the horizontal direction and $\boldsymbol{j}$ the unit vector in the vertical direction, then the position function is given by,

$$
r(t)=\left[V_{0} \cos (\theta) t\right] \boldsymbol{i}+h+\left[V_{0} \sin (\theta) t-\frac{1}{2} g t^{2}\right] \boldsymbol{j}
$$

where $V_{0}$ is the initial velocity of the roller coaster, $h$ is the starting height of the roller coaster, $\theta$ is the angle above the horizontal at which the coaster is launched, $g$ is the acceleration due to gravity and all distances are measured in feet. Substituting the values given in the problem into (1) yields:

$$
r(t)=[76.21 t] \boldsymbol{i}+\left[30+44 t-16 t^{2}\right] \boldsymbol{j}
$$

We differentiate (2) to obtain the velocity function,

$$
r^{\prime}(t)=v(t)=[76.21] \boldsymbol{i}+[44-32 t] \boldsymbol{j}
$$

The roller coaster will be at its maximum height when the velocity in the vertical direction is 0 ,

so we set $44-32 t=0$ to see $t=\frac{44}{32}=1.375$ seconds. Putting this time value into (2) we see the maximum height attainable by the roller coaster is $60.25 \mathrm{ft}$.

\section{DISCUSSION}

After completing all calculations, using the given information we found that the maximum height of the launch roller coaster would be $60.25 \mathrm{ft}$. The objective of this problem was met and it is very important to future development of roller coasters and amusement park rides. 


\section{CONCLUSION AND RECOMMENDATIONS}

Overall, this application of calculus proves to be very important to the field of engineering. When it comes to designing and constructing rides there are many calculations that need to be done. Without performing the appropriate steps to ensure things will run efficiently, it could not only ruin the project at hand, but cause money loss and danger. Without taking the time to perform these calculations and ensuring they are correct, it is very possible that a roller coaster could crash, valley out or put the riders in an overly dangerous situation.

With launch coasters being part of the new craze, it is imperative that we take the necessary precautions to ensure things are done properly. People's lives are at stake when it comes to projects of this magnitude and we would not want to be responsible for neglecting the safety of others. Understanding the intricacies of how a roller coaster works will allow engineers and ride designers to stay on the cutting edge and continue to produce gravity defying amusement park rides.

When it comes to this project, we would recommend that others look into the effect that the coaster will have after it has reached its maximum height. Coasters are not just one hill and done, they contain many different elements before and after what we have investigated here. Not only could we look at a launch roller coaster's maximum height, but at its acceleration and the force on the riders. This project highlights one of the many uses of calculus in real world applications. 


\section{NOMENCLATURE}

$r(t)$ : Position function for the launch roller coaster

$V_{0}$ : Initial velocity of the roller coaster

$\theta: \quad$ Angle at which the roller coaster is launched above the horizontal

$h$ : $\quad$ Initial height of the roller coaster in feet

g: Acceleration due to gravity

$v(t)$ Velocity function for the launch roller coaster

$t: \quad$ time in seconds

\section{REFERENCES}

Larson, Ron, Robert Hostetler and Bruce Edwards. Calculus. 8th Edition. Boston, MA: Houghton Mifflin Company, 2005. 